\title{
The Kinetics of Ethylene Decomposition on Iron Catalyst
}

\author{
I. PeŁECH* AND U. NARKIEWICZ \\ Institute of Chemical and Environment Engineering, West Pomeranian University of Technology \\ Pułaskiego 10, 70-322 Szczecin, Poland
}

\begin{abstract}
The effect of ethylene partial pressure and temperature on the hydrocarbon decomposition rate was studied. As a catalyst, a triply promoted iron catalyst (with addition of small amounts of potassium, calcium and alumina oxides) was used. The mean crystallites size was $c a .17 \mathrm{~nm}$. The processes were performed using pure ethylene or ethylene-nitrogen mixture under atmospheric pressure at the temperature range from 400 to $460{ }^{\circ} \mathrm{C}$. The growth of carbon mass as a function of reaction time was measured using a thermobalance. The phase composition of the samples after ethylene decomposition was determined using X-ray diffraction technique. The reaction rate was independent of ethylene partial pressure in the range from 0.25 to 1 bar. The maximal carbon yield for given experimental conditions was estimated.
\end{abstract}

PACS numbers: 81.70.Pg, 61.05.cp, 81.07.Bc, 81.16.Hc

\section{Introduction}

Ethylene is known as a good carbon source to obtain carbon nanotubes (CNTs). Hydrocarbon decomposition is carried out on transition metal catalysts: iron, cobalt, and nickel, most often on a support. The available papers concern mainly the influence of experimental conditions: kind of metal [1], catalyst support [2], flow rate and hydrocarbon concentration [3] or temperature and hydrogen role [4] on carbon yield and morphology of carbon nanostructures. There are only very few papers concerning the kinetics of the process.

Otsuka et al. [5] carried out decomposition of different hydrocarbons on $\mathrm{Ni} / \mathrm{SiO}_{2}$ catalyst. The initial rates of hydrocarbons decomposition, the kinetic curves of the decomposition, and the kinetics curves of hydrogenation of deposited carbon into methane depended on a type of carbon source. The life of $\mathrm{Ni} / \mathrm{SiO}_{2}$ catalyst decreased in the following order: alkanes $>$ alkenes $>$ acetylene. $\mathrm{Ni}$ et al. [6] studied kinetics of carbon nanotubes synthesis by the decomposition of methane over $\mathrm{Mo} / \mathrm{Co} / \mathrm{MgO}$ and $\mathrm{Co} / \mathrm{MgO}$ catalysts. On both catalysts, the rate of CNTs synthesis was proportional to the $\mathrm{CH}_{4}$ pressure, indicating that the dissociation of $\mathrm{CH}_{4}$ was the rate-determining step for a catalyst working without deactivation. The apparent activation energies were estimated to be $150-163 \mathrm{~kJ} / \mathrm{mol}$ and $96 \mathrm{~kJ} / \mathrm{mol}$ for $\mathrm{Mo} / \mathrm{Co} / \mathrm{MgO}$ and $\mathrm{Co} / \mathrm{MgO}$ catalysts, respectively. Kuvshinov et al. $[7,8]$ presented a mathematical model for the process of formation of nanofibrous carbon from the mixture of methane and hydrogen over $\mathrm{Ni} / \mathrm{Al}_{2} \mathrm{O}_{3}$ to describe the process kinetics involving the catalyst deactivation.

* corresponding author; e-mail: ipelech@zut.edu.pl
Fukada et al. [9] determined the decomposition rate of $\mathrm{CH}_{4}$ on a $\mathrm{Ni} / \mathrm{SiO}_{2}$ catalyst as a function of a flow rate, the $\mathrm{CH}_{4}$ concentration in a carrier gas, temperature, and the amount of carbon deposit. The decomposition reaction was of the first order and the overall decomposition rate constant was independent of the flow rate and the inlet $\mathrm{CH}_{4}$ concentration. Narkiewicz et al. [10] studied decomposition of methane on iron catalyst. The process rate was proportional to the hydrocarbon partial pressure. The determined apparent activation energy for the process of carbon deposit formation was about $150 \mathrm{~kJ} / \mathrm{mol}$. Khedr et al. [11] synthesized CNTs using acetylene and iron catalyst. They mentioned that both the crystal size and decomposition temperature had a significant effect on the yield of solid carbon formed. It increased with decreasing crystal size of catalyst and, to a certain level, with decomposition temperature. Liu et al. [12] and Lee et al. [13] studied decomposition of acetylene using also iron as a catalyst. The obtained activation energy for carbon nanotubes growth was equal to $160 \mathrm{~kJ} / \mathrm{mol}$ and $125 \mathrm{~kJ} / \mathrm{mol}$, respectively. Nevertheless, in the former work a surface reaction was proposed as rate determining step in the temperature range of $600-723^{\circ} \mathrm{C}$, in the latter diffusion limited growth model was suggested for the temperature range between 800 and $1100^{\circ} \mathrm{C}$. Juang et al. [14] performed systematic study to examine role of $\mathrm{NH}_{3}$ in the growth of CNTs in thermal chemical vapor deposition (CVD) under atmospheric pressure at various temperatures and acetylene $/ \mathrm{NH}_{3}$ ratios. Pirard et al. [15] performed a kinetic study of multi-walled carbon nanotubes synthesis over $\mathrm{Fe}-\mathrm{Co} / \mathrm{Al}_{2} \mathrm{O}_{3}$ catalysts, using ethylene as a carbon source. They reported that the best model assumed the elimination of the first hydrogen atom from adsorbed ethylene as a rate determining step and involved a hydrogen adsorption weak enough to 
be neglected. It was proved that hydrogen partial pressure had no influence on initial reaction rate of carbon nanotubes synthesis. Activation energy was found to be ca. $130 \mathrm{~kJ} / \mathrm{mol}$.

The aim of these studies is to investigate kinetics of carbon deposit formation on the triply promoted $\left(\mathrm{Al}_{2} \mathrm{O}_{3}\right.$, $\mathrm{CaO}, \mathrm{K}_{2} \mathrm{O}$ ) nanocrystalline iron. Kinetic studies are very helpful for the elucidation of the growth mechanism of CNTs and for the development of a large scale process of carbon nanotubes synthesis.

\section{Experimental details}

The studies of ethylene decomposition were carried out on a triply promoted nanocrystalline iron. The catalyst was obtained by fusion of magnetite $\left(\mathrm{Fe}_{3} \mathrm{O}_{4}\right)$ with small amounts of promoter oxides $\left(\mathrm{Al}_{2} \mathrm{O}_{3}, \mathrm{CaO}, \mathrm{K}_{2} \mathrm{O}\right)$ in an electric furnace. The role of promoter oxides was to stabilize the nanocrystalline iron structure at elevated temperatures. The obtained alloy was crushed and sieved in order to obtain a fraction of $1.2-1.5 \mathrm{~mm}$ and next was reduced under hydrogen. As a result of reduction nanocrystalline iron was obtained and the promoters remained in oxide state. In order to avoid rapid oxidation, the samples were passivated under nitrogen containing traces of oxygen. The composition of the reduced and passivated catalyst was determined using the inductively coupled plasma atomic emission spectrometry (ICP-AES) method (Yvon-Jobin). The samples contained iron and 2.92 wt. $\% \mathrm{Al}_{2} \mathrm{O}_{3}, 2.97$ wt. $\% \mathrm{CaO}$ and 0.65 wt. $\% \mathrm{~K}_{2} \mathrm{O}$. The mean crystallite size of iron determined using X-ray diffraction method (Co $K_{\alpha_{1}}$, Philips X'Pert) and calculated using Scherrer's equation amounted to ca. $17 \mathrm{~nm}$.

The reaction rate was measured using a thermogravimetric analysis. Ethylene decomposition processes were carried out in the thermobalance and they can be considered as performed in the differential reactor. The grains of iron catalyst were placed in one layer on the bottom of a platinum basket of thermobalance. In the first stage, the sample was reduced at the temperature rising from 20 to $500{ }^{\circ} \mathrm{C}$ under hydrogen atmosphere. The reduction process was performed in order to remove the passivation oxide layer from catalyst surface. When the catalyst mass was stabilized, reduction process was terminated and ethylene decomposition was started. Finally, the samples were cooled under nitrogen flow to the room temperature. Ethylene decomposition was performed under atmospheric pressure. The effect of temperature on the rate of carbon deposit formation was studied at a fixed temperature in the range of $400-460{ }^{\circ} \mathrm{C}$. The effect of the ethylene partial pressure on the rate of the carbon deposit formation was determined through the measurements of the reaction rate using ethylene-nitrogen mixture. The partial pressure of ethylene was varied by mixing ethylene with nitrogen in different ratios, keeping the fixed total flow velocity of the gas mixture.

The phase composition of solid samples after ethylene decomposition was determined using the X-ray diffraction method, Co $K_{\alpha_{1}}$ (Philips X'Pert).

\section{Results and discussion}

In our earlier studies [16] we found that as the result of hydrocarbon decomposition on the nanocrystalline iron catalyst two solid products are created: iron carbide in the form of cementite and carbon deposit. It was found that ethylene can be an effective carbon source for the growth of multi-walled carbon nanotubes. A quantity and quality of these materials depended on different parameters, such as: temperature, reaction time and the $\mathrm{C}_{2} \mathrm{H}_{4}: \mathrm{H}_{2}$ or the $\mathrm{C}_{2} \mathrm{H}_{4}$ : Ar ratio.

In order to study the influence of ethylene partial pressure and temperature on the carbon formation rate we selected suitable experimental conditions in which all iron is converted to iron carbide and carbon deposit is only created.

The samples of various mass weight were synthesised in the range from 0.2 to $0.8 \mathrm{~g} \mathrm{C} / \mathrm{g} \mathrm{Fe}$. It was impossible to get experimental points below $0.2 \mathrm{~g} \mathrm{C} / \mathrm{g} \mathrm{Fe}$; getting was impossible, because the reaction rate was too high. The phase composition of samples were characterized using X-ray diffraction method and diffraction patterns are presented in Fig. 1.

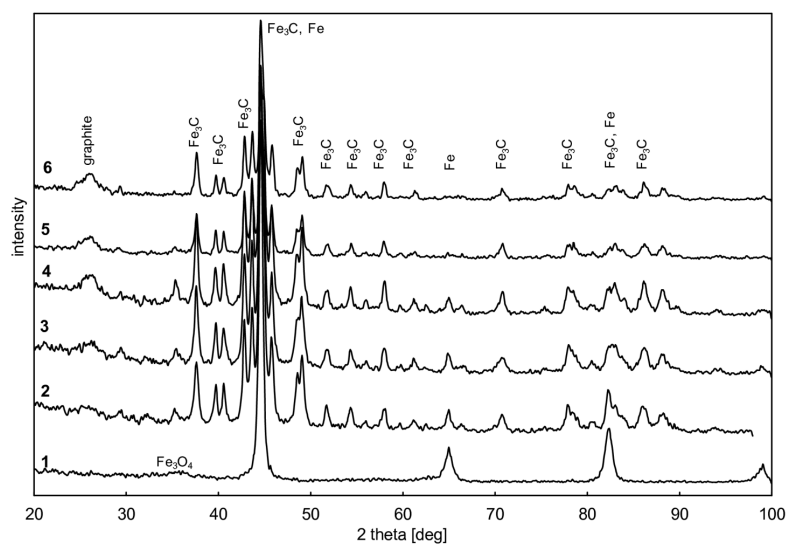

Fig. 1. Diffraction patterns of pure iron catalysts (1) and the samples after ethylene decomposition to the mass growth of: $0.20(2), 0.3$ (3), 0.50 (4), 0.67 (5) and 0.78 (6) $\mathrm{g} \mathrm{C} / \mathrm{g} \mathrm{Fe}$.

The first pattern corresponds to iron catalyst before the ethylene decomposition. The peaks attributed to $\alpha$-Fe can be observed. Additionally, in this sample the peak originating from iron oxide $\left(\mathrm{Fe}_{3} \mathrm{O}_{4}\right)$ is also observed, because metallic iron is very sensitive to oxidation and in contact with air the metal surface is partially oxidized. The following spectra (2-6) correspond to the samples after ethylene decomposition up to different carbon content. In these diffraction patterns, peaks corresponding to iron carbide in the form of cementite are present. Other iron carbides were not detected under these experimental conditions. The phase of graphite is also detected. The intensity of graphite peak increases together with the growth of carbon amount in the samples. 
In the diffraction patterns 3,4 and 5 , the peak attributed to unconverted $\alpha$-Fe can be also noticed, in spite of the fact that carbon amount was sufficient to convert all iron into $\mathrm{Fe}_{3} \mathrm{C}$. This indicates that in the range of relative increase of carbon mass from 0.2 to $0.6 \mathrm{~g} \mathrm{C} / \mathrm{g}$ Fe some part of carbon does not react to cementite and forms carbon deposit, then under these conditions a simultaneous formation of cementite and carbon deposit occurs.

In the diffraction pattern marked as 5 and 6 , peaks attributed to iron are no more observed. Therefore, in excess of $0.6 \mathrm{~g} \mathrm{C} / \mathrm{g}$ Fe only cementite and carbon deposit are created. For this stage the following studies described below were performed.

The dependence of ethylene decomposition reaction rate on cementite concentration is presented in Fig. 2. This relation was plotted on the basis of reaction rate obtained at different temperatures and of calculated values of cementite concentration in the particular samples. Cementite concentration can be defined as follows:

$$
C_{\mathrm{Fe}_{3} \mathrm{C}}=\frac{m_{\mathrm{Fe}_{3} \mathrm{C}}}{m_{\mathrm{Fe}}+m_{\mathrm{C}}}=\frac{1.072 m_{\mathrm{Fe}}}{m_{\mathrm{Fe}}+m_{\mathrm{C}}} .
$$

The presented curves correspond only to the carbon deposit formation and have a linear character at all temperatures of experiments. It is an indication that the reaction rate of carbon deposit formation is of the first order with respect to concentration of cementite.

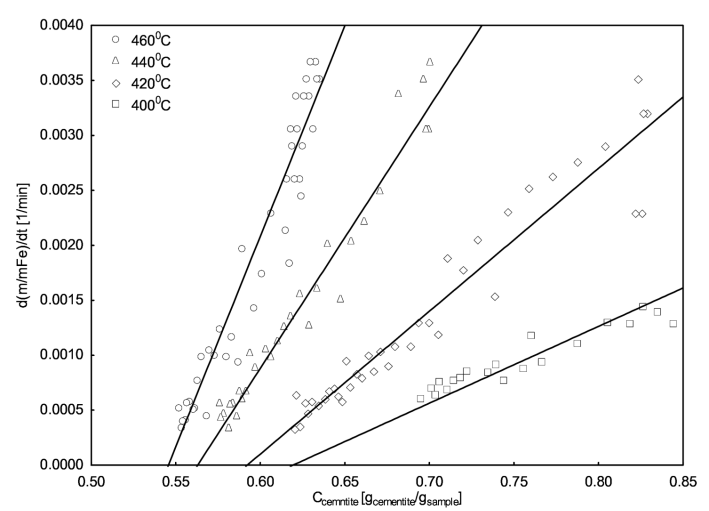

Fig. 2. The effect of cementite concentration on the reaction rate during the ethylene decomposition.

As a result of extrapolation of experimental data, a cementite concentration in the samples was calculated, for which the reaction rate would achieve zero level. Therefore we can determine a maximal carbon yield possible to be achieved at a given temperature.

In Table the values of cementite concentration and maximal carbon amount are presented. When the temperature increases, higher maximal carbon yield is obtained. This indicates that deactivation of catalyst connected with blocking of active sites for ethylene dissociative adsorption by carbon is faster at lower temperatures.

The effect of the ethylene partial pressure on the rate of ethylene decomposition to carbon deposit was determined through the measurements of the reaction rate us-
TABLE

The values of cementite concentration and maximal carbon yield at different temperatures.

\begin{tabular}{c|c|c}
\hline \hline Temperature $\left[{ }^{\circ} \mathrm{C}\right]$ & $C_{\text {cementite }}\left[\mathrm{g}_{\text {cementite }} / \mathrm{g}_{\text {sample }}\right]$ & $C_{\text {maximal }}\left[\mathrm{g}_{\mathrm{C}} / \mathrm{g}_{\mathrm{Fe}}\right]$ \\
\hline 400 & 0.007 & 0.72 \\
420 & 0.013 & 0.77 \\
440 & 0.024 & 0.83 \\
460 & 0.038 & 0.88
\end{tabular}

ing ethylene-nitrogen mixture. To obtain various ethylene pressures at the reactor inlet, the different ratios $\mathrm{C}_{2} \mathrm{H}_{4}-\mathrm{N}_{2}$ were applied. The processes were carried out at the constant flow amounting to $40 \mathrm{l} / \mathrm{h}$. As a result of ethylene decomposition, hydrogen is also formed. On the basis of ethylene partial pressure at the inlet of the reactor, of the methane flow velocity, and of the ethylene decomposition rate, the partial pressure of hydrogen was calculated and it did not exceed 0.05 bar, then it can be neglected. In Fig. 3 a dependence of reaction constant rates on ethylene partial pressure at $440^{\circ} \mathrm{C}$ is presented. The reaction constant rate at $440^{\circ} \mathrm{C}$ is equal to the tangent of the corresponding straight line in Fig. 2. The dependence of reaction rate on cementite concentration at the ethylene partial pressure were overlapped. Therefore it was found that under experimental conditions, ethylene partial pressure does not have influence on the reaction rate of carbon deposit formation (Fig. 3).

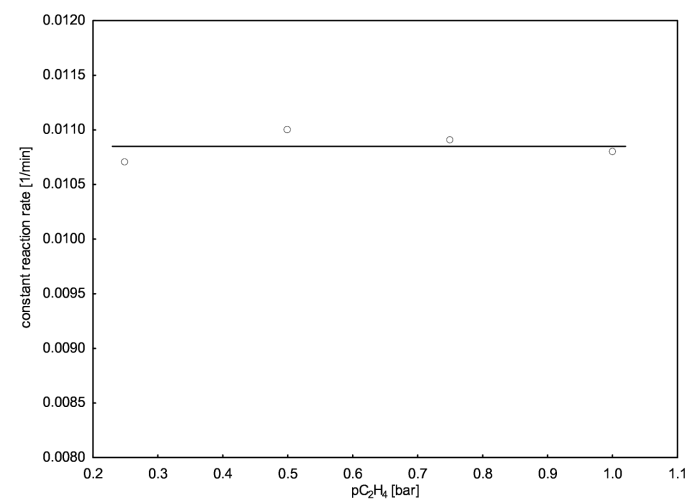

Fig. 3. The dependence of constant reaction rate on the ethylene partial pressure at $440^{\circ} \mathrm{C}$.

In order to determine the influence of ethylene decomposition temperature on the reaction rate, thermogravimetric measurements at the temperature range from 400 to $460^{\circ} \mathrm{C}$ were performed. In Fig. 4 the thermogravimetric curve shows the relative increase of carbon mass as a function of ethylene decomposition time at $440^{\circ} \mathrm{C}$, whereas the differential curve presents the ethylene decomposition rate as a function of reaction time. The dashed line corresponds to the stoichimetric composition of $\mathrm{Fe}_{3} \mathrm{C}$. The shape of obtained curves was similar for all the samples under the study. At the beginning of ethylene decomposition reaction rate was the highest and 


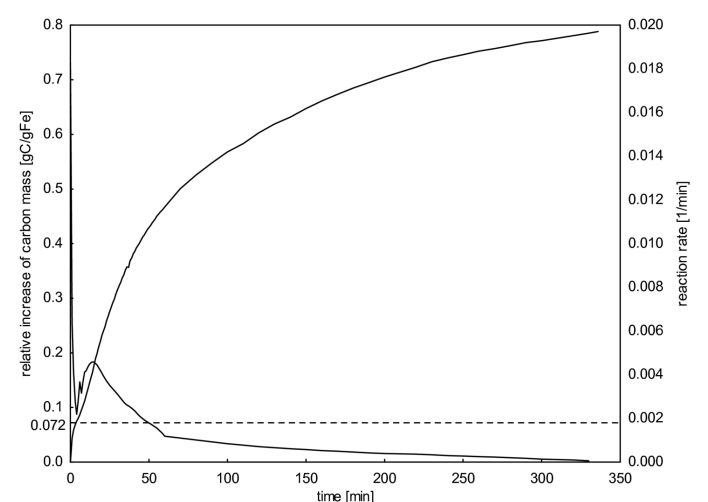

Fig. 4. Thermogravimetric (TG) and differential TG (DTG) curves of ethylene decomposition at $440{ }^{\circ} \mathrm{C}$.

proceeded on the active sites of iron. Simultaneously, a part of iron reacted with iron carbide. The rate of ethylene decomposition was too high to convert all iron crystallites to cementite. In the next stage the increase of reaction rate was observed as a result of decomposition of cementite to iron and carbon, according with carbide cycle described by Buyanov et al. [17]. According to this cycle, iron carbide is formed as a result of hydrocarbon reaction with iron. Cementite is a metastable phase and undergoes a thermal decomposition to carbon and iron. Carbon formed in this reaction segregates on surface, and iron reacts again with hydrocarbon, forming $\mathrm{Fe}_{3} \mathrm{C}$. At the same time a part of available iron surface is covered with carbon and thus during further ethylene decomposition a decrease of reaction rate is observed, connected with a blocking of part of active sites for ethylene dissociative adsorption by carbon deposit.

\section{Conclusions}

The effect of ethylene partial pressure and temperature on the reaction rate of ethylene decomposition to carbon deposit on iron catalyst was studied. Under the experiment conditions the rate of the carbon deposit formation is independent of the partial pressure of ethylene. At lower temperatures a lower maximal carbon yield can be obtained. This indicates that the deactivation of catalyst occurs faster at lower temperature.

\section{Acknowledgments}

This research was carried out under the funding of Polish Ministry of Science and Higher Education (NN $205112135)$.

\section{References}

[1] V.O. Khavrus, N.V. Lemesh, S.V. Gordijchuk, A.I. Tripolsky, T.S. Ivashchenko, M.M. Biliy, P.E. Strizhak, React. Kinet. Catal. Lett. 93, 295 (2008).

[2] N. Nagaraju, A. Fonseca, Z. Konya, J.B. Nagy, J. Mol. Catal. A, Chem. 181, 57 (2002).

[3] A.I. Tripol'skii, N.V. Lemesh, V.A. Khavrus', P.E. Strizhak, Theor. Exp. Chem. 44, 240 (2008).

[4] G. Gulino, R. Vieira, J. Amadou, P. Nguyen, M.J. Ledoux, S. Galvagno, G. Centi, C. Pham-Huu, Appl. Catal. A, General 279, 89 (2005).

[5] K. Otsuka, S. Kobayashi, S. Takenaka, Appl. Catal. A, General 210, 371 (2001).

[6] L. Ni, K. Kuroda, L.-P. Zhou, T. Kizuka, K. Ohta, K. Matsuishi, J. Nakamura, Carbon 44, 2265 (2006).

[7] S.G. Zavarukhin, G.G. Kuvshinov, Appl. Catal. A, General 272, 219 (2004).

[8] G.G. Kuvshinov, Yu.I. Mogilnykh, D.G. Kuvshinov, Catal. Today 42, 357 (1998).

[9] S. Fukada, N. Nakamura, J. Monden, M. Nishikawa, J. Nucl. Mater. 329-333, 1365 (2004).

[10] U. Narkiewicz, W. Arabczyk, W. Konicki, I. Kucharewicz, Rev. Adv. Mater. Sci. $\mathbf{8}, 53$ (2004).

[11] M.H. Khedr, K.S. Abdel, N.K. Halim, Soliman, Appl. Surf. Sci. 255, 2375 (2008).

[12] K. Liu, K. Jiang, C. Feng, Z. Chen, S. Fan, Carbon 43, 2850 (2005).

[13] Y.T. Lee, J. Park, Y.S. Choi, H. Ryu, H.J. Lee, J. Phys. Chem. B 106, 7614 (2002).

[14] Z.Y. Juang, J.F. Lai, C.H. Weng, J.H. Lee, H.J. Lai, T.S. Lai, C.H. Tsai, Diam. Relat. Mater. 13, 2140 (2004).

[15] S.L. Pirard, S. Douven, C. Bossuot, G. Heyen, J.-P. Pirard, Carbon 45, 1167 (2007).

[16] U. Narkiewicz, I. Pełech, W. Arabczyk, K. Biedermann, Ch. Tüchner, Polish J. Chem. 82, 1743 (2008).

[17] R.A. Buyanov, V.V. Chesnokov, A.D. Afanasev, V.S. Babenko, Kinet. Katal. 4, 1021 (1997). 